\title{
Bibliografía sobre adaptaciones de la literatura española al cine en el nuevo milenio $(2001-2020)^{1}$
}

\author{
MANUEL ESPAÑA ARJONA \\ Universidad de Málaga \\ manuelesp@uma.es \\ ORCID ID: 0000-0001-5751-1707
}

Como complemento al catálogo de adaptaciones publicado en este mismo número 3 de Trasvases entre la literatura y el cine, ofrecemos aquí un repertorio bibliográfico que recoge las aportaciones académicas (con algunas excepciones en forma de trabajos más divulgativos cuando su calidad y pertinencia lo han aconsejado) sobre dichas películas. Este listado, ordenado de forma cronológica en correlación con el corpus filmográfico, incluye solo los trabajos relacionados con las adaptaciones, no así los análisis centrados exclusivamente en los aspectos cinematográficos. Hay casos, eso sí, en los que la vinculación con el texto literario es más tenue, pero pueden contribuir a iluminar algún aspecto, menor pero significativo, de la adaptación.

Su doble objetivo es proporcionar auxilio bibliográfico para emprender estudios sobre estas adaptaciones del nuevo milenio, y revelar cuáles no han sido aún abordadas desde el prisma de su tránsito de la literatura al cine. A ello se encomienda el apéndice, dispuesto alfabéticamente, para incentivar el análisis de esos casos. Naturalmente, cualquier error/omisión en el listado que se comunique a la revista será muy bien recibido para que paulatinamente se vayan perfeccionando los corpus de estudio que tenemos intención de ofrecer en adelante.

\footnotetext{
${ }^{1}$ Este trabajo se encuadra en el Proyecto del Plan Propio de Investigación y Transferencia de la Universidad de Málaga Reescrituras de la novela en el cine y la ficción televisiva (2020-21).
} 


\section{Juana la Loca}

ARANDA, Vicente (2002), «Juana la Loca. Juana la Loca y su locura de amor», Academia, 32, 2002, págs. 18-27.

Caparrós Lera, José María (2003), «¿Historia o leyenda?: Juana la Loca (2001), de Vicente Aranda. Breve estudio comparativo con Locura de amor (1948), de Juan de Orduña, según la pieza escénica de Tamayo y Baus», Studi Ispanici, 6, págs. 83-90.

Dávila Vargas-MachuCA, Miguel (2019), «Las pasiones de Juana la Loca en el cine español desde la Historia y el Teatro a las adaptaciones, readaptaciones y remakes compuestos», Trasvases entre la literatura y el cine, 1, págs. 97-128 [En línea: https://revistas.uma.es/index.php/trasvases/article/view/643 5/6918].

DONAPETRY, María (2005), «Juana la Loca en tres siglos: de Tamayo y Baus a Aranda pasando por Orduña», Hispanic Research Journal, 6/2, págs. 147-154.

FITTS, Alexandra (2013), «The Seductive Narrative Appeal of a Madwoman Juana "la Loca" and Excessive Feminity», Hipertexto, 17, págs. 3-15 [En línea: https://www.utrgv.edu/hipertexto/ files/documents/articles /hipertexto-17/alexandra-fitts.pdf].

Gavela, Yvonne (2016), «Mediación y memoria en la creación de un mito en la pantalla: Juana la Loca», Crítica hispánica, 38/1, págs. 75-94.

GómEZ, María Asunción (2006), «Mujer, nación y deseo en Locura de amor de Juan de Orduña y Juana La Loca de Vicente Aranda», Filmhistoria, 16, $1 / 2 \quad$ [En línea: http://www.publicacions.ub.edu/bibliotecaDigital/cinema/fil mhistoria/2006/REVISTAS/Ensayo MujerNacionDeseo\%20 1 . htm].

LÓPEZ LÓPEZ, Yolanda (2004), «Visiones sobre Juana la Loca: las recreaciones de Juan de Orduña y Vicente Aranda», en J. Cabeza y A. Rodríguez (coords.), Creando cine, creando historia: la representación cinematográfica de ideas y movimientos sociales, Madrid, Universidad Complutense, págs. 117-130.

PÉREZ BOWIE, José Antonio (2008), «La adaptación como reescritura. Algunos ejemplos de la filmografía de Vicente Aranda», en A. Notari Ruiz (ed.), Estética: Perspectivas contemporáneas, Universidad de Salamanca, págs. 67-88. 
Bibliografía sobre adaptaciones de la literatura española al cine

SMiTh, Paul Julian (2004), «Patrimonio español, cine español. El extraño caso de Juana la Loca», Res pública, 13/14, págs. 297-308 [En

línea:

https: //revistas.um.es/respublica/article/view/59961/57771].

SOLIÑo, María Elena (2005), «La iconografía de Juana la loca. Representaciones de la locura femenina en pintura, teatro y cine», en M. Ángel Candelas Colodrón et al. (coords.), Reescribir ficciones: imágenes de la literatura en el cine y la televisión, Vigo, Mirabel, págs. 249-266.

\section{Son de mar}

HAFTER, Lea Evelyn (2008), «Tras las huellas del guionista: la mirada de Rafael Azcona sobre Martina en Son de mar», Olivar, 9/12, págs. 263-274 [En línea: http://www.memoria.fahce.unlp.edu.ar/art_revistas/pr. 3718 /pr.3718.pdf].

MALPARTIDA TiRADO, Rafael (2012), «El erotismo, de la novela al cine: El caso de Bigas Luna», AnMal electrónica, 32, págs. 175-196 [En línea: http://www.anmal.uma.es/numero32/Bigas Luna.pdf].

El bosque animado

ÚBeDA PORTUGuÉs, Alberto (2005), «El bosque animado: nosotros, los hijos de Cécebre», en M. Miguel Borrás (coord.), La letra en el cine: escritores en el cine europeo, Madrid, Universidad Francisco de Vitoria, págs. 45-50.

\section{Manolito Gafotas en ;Mola ser jefe!}

GARCÍA MÉRIDA, Marina (2019), «Entrevista a Elvira Lindo», Trasvases entre la literatura y el cine, 1, págs. 209-216 [En línea: [https: //revistas.uma.es/index.php/trasvases/article/view/667 8/6906].

GARCía MÉRIDA, Marina (2020), La obra narrativa de Elvira Lindo y sus adaptaciones al cine, Universidad de Málaga, págs. 227-399 [Tesis doctoral] [En línea: https://riuma.uma.es/xmlui/handle/10630/21084].

\section{Lázaro de Tormes}


DíEZ MÉNGuEZ, Isabel Cristina (2008), «La adaptación cinematográfica del Lazarillo de Tormes, por Fernando FernánGómez y José Luis García Sánchez», en J. Nicolás Romera Castillo (coord.), Teatro, novela y cine en los inicios del siglo XXI: actas del XVII Seminario Internacional del Centro de Investigación de Semiótica Literaria, Teatral y Nuevas Tecnologías, Madrid, Visor Libros, págs. 403-415.

DraysON, Elizabeth (2013), «From Text to Image and Film: two visual recreations of Lazarillo de Tormes by Francisco de Goya and Fernando Fernán Gómez», en I. Medina Barco (ed.), Literature and Interarts: Critical Essays, Logroño, Universidad de La Rioja, págs. $145-162$

[En

línea:

https://publicaciones.unirioja.es/catalogo/online/interarts/pdf 107 Drayson.pdf].

ESPAÑa ARJONA, Manuel (2018), «Tres lazarillos fílmicos y otros casos», Quimera, 410, págs. 18-21.

Fernando TAPia, Carlos (2007), Ink and Celluloid: A Study of the Lazarillo de Tormes and Its Filmic Adaptations, Georgetown University [Tesis doctoral] [En línea: https: //pqdtopen.proquest.com/doc/304876182.html?FMT= AI].

GonZÁlez Miranda, Marta (2005), «Las funciones del espacio en el Lazarillo de Tormes: texto literario y texto fílmico», en M. Á. Candelas Colodrón et al. (coords.), Reescribir ficciones: imágenes de la literatura en el cine y la televisión, Vigo, Mirabel, págs. 121-134.

LEMOS GONZÁleZ, David (2011), «El Lazarillo en Lázaro de Tormes», en A. A. Galiana y S. Fernández Mosquera (coords.), Compostella aurea. Actas del VIII Congreso de la Asociación Internacional del Siglo de Oro. III, Universidad de Santiago de Compostela, págs. 337-345 [En

https://minerva.usc.es/xmlui/bitstream/handle/10347/10670 /pg 338-347 cc197b.pdf? sequence $=1$ \&isAllowed $=\mathrm{y}]$.

MalPaRTIDA TiRADO, Rafael (2018), «El componente verbal en las adaptaciones de la literatura áurea española al cine y la televisión: una propuesta de estudio», Edad de Oro, XXXVII, págs. 184-227 [En línea: https: //revistas.uam.es/edadoro/article/view/10288/10449].

Moriche Hermoso, Pedro Jesús (2012), «El recurso de la inventio en la adaptación cinematográfica del Lazarillo de Tormes», Fonseca, 4, págs. [En 103-117 línea: https: //revistas.usal.es/index.php/21729077/article/view/12055/12398]. 
Bibliografía sobre adaptaciones de la literatura española al cine

Rodríguez Mansilla, Fernando (2013), «Lázaro de Tormes de Fernando Fernán-Gómez: hacia una lectura postnacional del Lazarillo de Tormes», Hispanófila, 169, págs. 81-91.

TrecCA, Simone (2008), «La palabra al pícaro: Lázaro de Tormes (2000), de Fernando Fernán-Gómez y José Luis García Sánchez», en J. N. Romera Castillo (coord.), Teatro, novela y cine en los inicios del siglo XXI: actas del XVII Seminario Internacional del Centro de Investigación de Semiótica Literaria, Teatral y Nuevas Tecnologías, Madrid, Visor Libros, págs. 575-584.

\section{Amor, curiosidad, prozak y dudas}

FreiXAs, Ramón y Marcos Martínez DomíngueZ (2005), «Etxebarria / Santesmases: Amor, curiosidad, Prozac y dudas», en M. Á. Candelas Colodrón et al. (coords.), Reescribir ficciones: imágenes de la literatura en el cine y la televisión, Vigo, Mirabel, págs. 381-392.

GAVELA-RAmos, Yvonne (2012), «La adaptación fílmica de la narrativa de la "generación X" en la España de los noventa», en B. Zecchi (ed.), Teoría y práctica de la adaptación fílmica, Madrid, Universidad Complutense, págs. 161-175.

\section{Salvajes}

Alonso de SAntos, José Luis (2001), «Del teatro al cine», en Salvajes. Guión cinematográfico, Madrid, Ocho y Medio, págs. 133-135.

AlOnSO de SANTOS, José Luis (2002), «De la escritura dramática a la escritura cinematográfica», en J. Romera Castillo (ed.), Del teatro al cine y la televisión en la segunda mitad del siglo XX, Madrid, Visor Libros, págs. 17-24.

Gutiérrez Carbajo, Francisco (2004), «Carlos Molinero y su interpretación fílmica de la obra teatral Salvajes, de José Luis Alonso de Santos», Signa, 13, págs. 173-184 [En línea: http://revistas.uned.es/index.php/signa/article/view/6093/5 $\underline{828}]$.

SIEBER, Cornelia (2020), «Transmedial Encroachment and the Urgency of the Conflicts of Migration in Salvajes (Carlos Molinero, Spain, 2001)», en C. Sieber y A. de Toro (eds.), On Migration: Diasporization - Transculturality - Transmediality, Hildesheim, OLMS, págs. 123-130.

\section{La isla del holandés (L'illa del l'holandès)}


Domenin, Elena (2016), La identidad desde un punto de vista personal y espacial en Lucía y el sexo y L'illa de l'holandés, Università Ca' Foscari Venezia [Tesis doctoral].

\section{Hermanas de sangre (Germanes de sang)}

González Herrán, José Manuel (2009), «Hermanas de sangre, una pieza teatral de Cristina Fernández Cubas (1998) filmada para televisión por Jesús Garay (2001)», Lectura, imágenes, 6, págs. 111 137.

Vilardell Grimau, Teresa (2016), Les adaptacions cinematogràfiques d'obres teatrals a Catalunya 2000-2010. Disseny i procediments compositius, Universitat Autònoma de Barcelona [Tesis doctoral].

\section{Amar y morir en Sevilla (Don Juan Tenorio)}

GIES, David T. (2008), «Don Juan Tenorio, estrella de cine: Zorrilla, Mercero, Barrera», en J. F. Botrel et al. (eds.), La Literatura Española del Siglo XIX y las artes (Barcelona, 19-22 de octubre de 2005), Universidad de Barcelona, págs. 163-174.

Utrera Macías, Rafael (2007), «Don Juan: una panorámica», en Literatura y cine. Adaptaciones I. Del teatro al cine, Sevilla, Padilla Libros, Cuadernos de EIHCEROA, págs. 81-120 [En línea: https: //idus.us.es/handle/11441/31844].

\section{Anita no pierde el tren}

Rams, Maribel (2014), «La projecció de la ciutat al cinema de Ventura Pons», Zeitschrift für Katalanistik, 27, págs. 47-67 [En línea: http://www.romanistik.unifreiburg.de/pusch/zfk/27/07 Rams.pdf].

\section{2}

\section{Cásate conmigo, Maribel}

LÓPEZ IZQUIERDO, Javier (2005), «Me quiero casar contigo: el complicado trance de la declaración en el cine de Miguel Mihura», Quimera, 257, págs. 36-39.

VAlLECILlO LÓPEZ, José (2003), «Análisis de una adaptación para televisión de Maribel y la extraña familia de Miguel Mihura», en A. Romero Ferrer y M. Cantos Casenave (eds.), La comedia española. Entre el realismo, la provocación y las nuevas formas (1950-2000): actas 
Bibliografía sobre adaptaciones de la literatura española al cine

del IV y V Congreso Internacional de Historia y Critica del Teatro de Comedias, Puerto de santa María, abril de 2000 y 2002, Universidad de Cádiz, págs. 397-403.

\section{El alquimista impaciente}

Arroyo MartíneZ, Laura (2013), «El alquimista impaciente, de Lorenzo Silva: estudio de una adaptación», en J. Sánchez Zapatero y À. Martín Escribà (eds.), Historia, memoria y sociedad en el cine negro: literatura, cine, televisión y cómic, Santiago de Compostela, Andavira, págs. 323-328.

Essissima, Michel-Yves (2012), Estudio de las interrelaciones de lenguajes en "El alquimista impaciente" y "Pudor", UNED [Tesis doctoral] [En línea:

http://e-

spacio.uned.es/fez/eserv.php?pid=tesisuned:Filologia-

Myessissima\&dsID=Documento.pdf].

PÉreZ Millán, Juan Antonio (2006), «Tres ejemplos de cine negro: El sueño eterno, Sed de mal y El alquimista impaciente», en Á. Martín Escribà y J. Sánchez Zapatero, Manuscrito criminal: Reflexiones sobre novela y cine negro, Universidad de Salamanca, págs. 223-233.

\section{El caballero don Quijote}

AltenberG, Tilmann (2007), «Don Quijote im Film», en T. Altenberg y K. Meyer-Minnemann (eds.), Europäische Dimensionen des "Don Quijote" in Literatur, Kunst, Film und Musik, Hamburg University, págs. 171-234 [En línea: https: / /library.oapen.org/viewer/web/viewer.html?file=/bits tream $/$ handle $/ 20.500 .12657 / 27665 / 1002340$.pdf?sequence $=1$ \&isAllowed $=\mathrm{y}$ ].

Ardila Rojas, Felipe y CÁrdenas PÁez (2008), «Don Quijote de la Mancha: Reflexiones en torno a las relaciones cine-literatura», Folios, 27, págs. 97-110 [En línea: https://revistas.pedagogica.edu.co/index.php/RF/article/view /6097/5056].

Blanco Mallada, Lucio (2008), «Don Quijote en el cine de ficción español», en F. B. Pedraza Jiménez y R. González Cañal (coords.), Con los pies en la tierra. Don Quijote en su marco geográfico e histórico: XII Coloquio Internacional de la Asociación de Cervantistas (XII-CIAC), Argamasilla de Alba, Universidad de Castilla-La Mancha, págs. 473-490 [https://pdfslide.tips/reader/f/don-quijote-en-el-cinede-ficcion-espanol-este-don-quijote-de-representando]. 
BOER, Harm Den (2009), «En cierto sentido, él es España. Sobre Don Quijote llevado al cine», en M. Kunz (ed.), Quijotextos, Quijotemas, Quijoterías. Ocho acercamientos a Don Quijote, University of Bamberg, págs. 173-209 [https: / /www.academia.edu/5985758/En cierto sentido \%C 3\%A9l es Espa\%C3\%B1a Sobre Don Quijote llevado al cin e].

BRIONES, Luisa (2012), «Los Quijotes de Gil, Gutiérrez Aragón, Welles y Gavaldón: nuevas aproximaciones teóricas», en B. Zecchi (ed.), Teoría y práctica de la adaptación fílmica, Madrid, Universidad Complutense, págs. 85-97.

BuEzo, Catalina (2008), «El caballero Don Quijote, de Manuel Gutiérrez Aragón: de la novela al cine», en J. Romera Castillo (coord.), Teatro, novela y cine en los inicios del siglo XXI: actas del XVII Seminario Internacional del Centro de Investigación de Semiótica Literaria, Teatral y Nuevas Tecnologías, Madrid, Visor Libros, págs. 389-402.

ESPAÑA, Rafael de (2007), De la Mancha a la pantalla. Aventuras cinematográficas del Ingenioso Hidalgo, Universidad de Barcelona.

García-Rayo, Antonio (2004), «Don Quijote y Sancho Panza cabalgan por el cine, AGR coleccionistas de cine, 6/22, págs. 106146.

Gupta, Sonya S. (2008), «Media Representations of Don Quixote by Manuel Gutiérrez Aragón», en V. Maurya e I. Arellano Ayuso (coords.), Cervantes and "Don Quixote": proceedings of the Delhi Conference on Miguel de Cervantes, Hyderabad, Emesco, págs. 377392

https: / /cvc.cervantes.es/literatura/cervantistas/conferencias/c f dcmc/cf demc 26.pdf].

Gutiérrez Carbajo, Francisco (2006), «Lenguaje literario y lenguaje fílmico. Versión cinematográfica de El caballero Don Quijote de Manuel Gutiérrez Aragón y sus antecedentes», Filología y lingüística, 1, págs. 1987-1998.

Heredero, Carlos F. (2004), «La simiente cervantina», en Carlos F. Heredero (ed.), Manuel Gutiérrez Aragón: las fábulas del cronista, Madrid, SGAE/Ocho y Medio, págs. 139-156.

HERnÁNDEZ, Javier (2005), «Manuel Gutiérrez Aragón o los Quijotes de la democracia», Nosferatu, 50, págs. 18-22 [En línea: https: //riunet.upv.es/bitstream/handle/10251/41421/NOSF ERATU 050 003.pdf].

HerranZ, Ferrán, El Quijote y el cine, Madrid, Cátedra, 2005.

KerChER, Dona M. (2002), «Looking for Don Quijote's Own Shadow: an Interview with Manuel Gutiérrez Aragón about His 
Bibliografía sobre adaptaciones de la literatura española al cine

Film El caballero Don Quijote», Arizona Journal of Hispanic Cultural Studies, 6, págs. 129-140 [En línea: https: //muse.jhu.edu/article/378593/pdf].

Malpartida TiRAdo, Rafael (2018), «El componente verbal en las adaptaciones de la literatura áurea española al cine y la televisión: una propuesta de estudio», Edad de Oro, XXXVII, págs. 184-227 [En línea: https: / /revistas.uam.es/edadoro/article/view/10288/10449].

NeIra PiñeIro, María del Rosario (2008), «El Quijote en su transposición al medio cinematográfico: problemas de la adaptación», en M. Á. Garrido Gallardo y L. Alburquerque García (coords.), El Quijote y el pensamiento teórico-literario, Madrid, CSIC, págs. 399-406.

PayÁn, Miguel Juan (coord.) (2005), El Quijote en el cine, Madrid, Jaguar, 2005.

Puig, Mi (2016), «La representación de la amistad en El caballero don Quijote (2002) de Manuel Gutiérrez Aragón», en C. Mata Induráin, Recreaciones Quijotescas y cervantinas en las artes. Cervantes y su obra, Pamplona, EUNSA, págs. 145-158 [En línea: https://espace.mmu.ac.uk $/ 617631 / 10 / \mathrm{amistad} \% 20 \mathrm{en} \% 20 \mathrm{el} \% 20$ cine $\% 2$ Oversion $\% 20$ final $\% 20 \% 281 \% 29$.pdf .

REINSTÄDLER, Janett (2019), «Los sueños de Don Quijote en el cine: dinámicas transmediales», Ibero, 90, págs. 151-171.

SÁNCHEZ NORIEGA, José Luis (2005), «Humor y utopía en los Quijotes de Manuel Gutiérrez Aragón», Boletín de la Biblioteca Menédez Pelayo, 81, págs. 493-515 [En línea: https://eprints.ucm.es/id/eprint/50498/1/Humor y utopia en los Quijotes de Manuel.pdf].

Santos Aparicio, Antonio (2004), «A Cervantic Prelude: From Don Quixote to Postmodernism», Literature Through Film: Realism, Magic, and the Art of Adaptation, Oxford, Blackwell Publishing, págs. 2262.

SANTOS Aparicio, Antonio (2006), El sueño imposible: aventuras cinematográficas de Don Quijote y Sancho, Santander, Fundación Marcelino Botín.

Shu-Ying Chang, Luisa (2005), «El Quijote en el cine de Manuel Gutiérrez Aragón», en A. Close (ed.), Actas del VI Congreso de la Asociación Internacional del Siglo de Oro (AISO), Madrid, AISPO, págs. 161-166 [En línea: https://cvc.cervantes.es/Literatura/aiso/pdf/07/aiso 7 020.p df]. 


\section{El embrujo de Shanghai}

Castellani, Jean Pierre (2009), «Dos ciudades en el cine y la literatura: Barcelona y Shangai», Ángulo Recto, 1/1, s.p. [En línea: https: //revistas.ucm.es/index.php/ANRE/article/view/ANRE 0909220003A/6139].

Castellani, Jean Pierre (2011), «Barcelona y Shangai, entre cine y literatura», Revista de Filología Románica, 2, págs. $71-78$ [En línea: https://revistas.ucm.es/index.php/RFRM/article/view/RFR M0808330071A/9295].

Christensen, Jessie Louise (2007), Beyond Fidelity: The Translation Process in Two Adaptations of Juan Marsé's "El embrujo de Shanghai" (2007), Brigham Young University [Thesis Master of Arts] [En línea: https://scholarsarchive.byu.edu/etd/906/].

Deveny, Thomas (2003), «Narrativa Voice in El embrujo de Shangai: novel, promise, film», Letras peninsulares, 16/3, págs. 719-738.

GutiÉRreZ Carbajo, Francisco (2003), «Los guiones de El embrujo de Shanghay de Juan Marsé», en J. Antonio Pérez Bowie (ed.), La adaptación cinematográfica de textos literarios. Teoría y práctica, Salamanca, Plaza Universitaria, págs. 97-113.

Kwang-HeE, Kim (2005), «La fidelidad traidora: El Embrujo de Shangai, de Fernando Trueba», Revista canadiense de estudios hispánicos, 2/29, págs. 327-346.

Romea Castro, Celia (2003), «El embrujo de Shangai: impacto de relecturas», Letras peninsulares, 1/16, págs. 41-76.

TENA, Jean (2004), «Una novela, dos guiones: El embrujo / La promesa de Shangai (J. Marsé, V. Erice, F. Trueba)», Studi Ispanici, 7, págs. 85 99.

2003

\section{El lápiz del carpintero}

FERnÁNDEZ-Ramos, Veza María (2010), La adaptación al cine de la novela de la Guerra Civil española, Universität Graz [Tesis doctoral] [En línea: https://unipub.unigraz.at/obvugrhs/download/pdf/211494?originalFilename $=$ tru e].

GARcíA-ABAD GARcía, María Teresa (2005), «"El ajuar de la memoria": un imperativo ético y estético en El lápiz del carpintero, de Rivas, Cuña y Reixa», Intermedios. Estudios sobre literatura, teatro y cine, Madrid, Fundamentos, págs. 178-198. 
Bibliografía sobre adaptaciones de la literatura española al cine

\section{La flaqueza del bolchevique}

Malpartida Tirado, Rafael (2015), «Subjetividad y adhesión emocional en dos adaptaciones de la novela al cine», Signa, 24, págs. [En 125-148 línea: http://revistas.uned.es/index.php/signa/article/view/14725/ $\underline{13140]}$.

\section{La luz prodigiosa}

Dinverno, Melissa (2007), «Wounded Bodies: García Lorca, Memory, and the Ghostly Return of the Past in Miguel Hermosos's La luz prodigiosa», Anales de Literatura Española Contemporánea, 1/32, págs. 5-36.

\section{Palabras encadenadas}

Ferrer Hammerlindl, Carlos (2012), «El teatro en el cine: el caso de Jordi Galcerán», en R. Alemany Ferrer y F. Chico Rico (eds.), XVIII Simposio de la SELGYC (Alicante 9-11 de septiembre 2010) = XVIII Simposi de la SELGYC (Alacant 9-11 setembre de 2010). Literatura i espectacle $=$ Literatura y espectáculo, Universidad de Alicante / SELGYC, págs. 225-234 [En línea: http://www.cervantesvirtual.com/obra/el-teatro-en-el-cine-el-caso-de-jordi-galceran//].

\section{Soldados de Salamina}

Amago, Samuel (2012), «La adaptación como cartografía en Soldados de Salamina», en B. Zecchi (ed.), Teoría y práctica de la adaptación filmica, Madrid, Universidad Complutense, págs. 239-255.

BALLESTEROS, Isolina (2005), «La exhumación de la memoria histórica: nostalgia y utopía en Soldados de Salamina (Javier Cercas, 2001; David Trueba, 2002)», Filmhistoria online, 15/1 [En línea: http: / / www.publicacions.ub.es/bibliotecadigital/cinema/filmh istoria/2005/Ensayo Soldados\%20de\%20Salamina\%20 1.htm]

BORgES, Samantha y André SOARES VIEIRA (2013), «Literatura comparada e adaptação cinematográfica: a marcha de Soldados de Salamina», Cuaderno Seminal Digital, 20/20, págs. 162-185 [En línea:

https: //www.e- 
publicacoes.uerj.br/index.php/cadernoseminal/article/view/1 2020/9407].

C. Mabrey, María Cristina (2007), «Experiencia de la memoria o memoria de la experiencia: novela y film, Soldados de Salamina», Espéculo, [En 37 línea: https://webs.ucm.es/info/especulo/numero37/salamina.html]

Caparrós Lera, José María (2005), «Soldados de Salamina», en La pantalla popular. El cine español durante el Gobierno de la derecha (1996-2003), Madrid, Akal, págs. 221-223.

Cercas, Javier y David Trueba (2003), Diálogos de Salamina: un paseo por el cine y la literatura, Barcelona/Madrid, Tusquets/Plot.

Cogotti, Carla Maria (2012), «Dal romanzo al film: Soldados de Salamina e il paradosso del tradimento fedele», Between, II/4 [En línea: https://www.researchgate.net/profile/CarlaCogotti/publication/280919727_Dal_romanzo_al_film_Soldad os de Salamina e il paradosso del tradimento fedele/links/ 55cb16a308aebc967dfbfd38/Dal-romanzo-al-film-Soldados-deSalamina-e-il-paradosso-del-tradimento-fedele.pdf].

García Jambrina, Luis Miguel (2004), «De la novela al cine: Soldados de Salamina o El Arte de la Traición», Ínsula, 688, págs. 30-32.

García-Reyes, David (2020), «Reescrituras en Soldados de Salamina o las sendas de la memoria: desplazamientos de la literatura en el cine y en la narración figurativa», Trasvases entre la literatura y el cine, 2, págs. 271-291 [En línea: https://revistas.uma.es/index.php/trasvases/article/view/919 $\underline{1 / 10539]}$.

Hermans, Hubertus (2008), «El silencio llevado al cine: Cercas, Trueba y los Soldados de Salamina», Foro hispánico, 32, págs. 77-97.

HugHes, Arthur (2007), «Between History and memory: creating a new subjectivity in David Trueba's Film Soldados de Salamina», Bulletin of Spanish Studies, 84/3, págs. 369-386.

IbáÑEZ FanÉs, Jordi (2003), «Ire ad Plures: Soldados de Salamina, el libro y la película», El Viejo topo, 179, págs. 72-77.

Latorre Ceresuela, Yolanda (2005), «Soldados de Salamina: Cruce de voces, convergencia de medios narrativos», en M. Ángel Candelas Colodrón et al. (coord.), Reescribir ficciones: imágenes de la literatura en el cine y la televisión, Vigo, Mirabel, págs. 57-66.

Minardi, Adriana (2014), «Politics of Memory and Politics of Forgetting: Hermeneutics of Intermediality in Soldados de Salamina», en J. Brady et al. (eds.), Collapse, Catastrophe and 
Bibliografía sobre adaptaciones de la literatura española al cine

Rediscovery: Spain's Cultural Panorama in the Twenty-First Century, Cambridge Scholars, págs. 59-72.

PÃunescu, Ana-Maria (2015), «Soldados de Salamina. Dos enfoques, la misma guerra. Los tres $\mathrm{P}$ de la curiosidad contemporánea: perspectivas, preguntas y pormenores», en E. Camarero y $\mathrm{M}$. Marcos (coords.), III Congreso Internacional de Histora, Literatura y Arte en el Cine en español y portugués. Hibridaciones, transformaciones y nuevos espacios narrativos, Salamanca, Hergar Ediciones Antema, págs. [En 655-666 línea: https: / / congresocinesalamanca2015.files. wordpress.com/2016 /05/salamanca-actas-tomo-1.pdf].

Peris Blanes, Jaume (2012), «Los agujeros del “relato real”. Usos del archivo y del testimonio en Soldados de Salamina (Cercas/ Trueba)», Archivos de la filmoteca, 70, págs. 139-150.

SÁNCHEZ ZAPATERO, Javier (2014), «La intertextualidad literaria en Soldados de Salamina, de David Trueba», en P. J. Pardo García y J. Sánchez Zapatero (coords.), Sobre la adaptación y más allá: trasvases filmoliterarios, Universidad de Salamanca, págs. 227-236.

YIM, Ho-Joon (2015), «La sintonización de la perspectiva política con su tiempo y género: adaptación cinematográfica de la novela Soldados de Salamina», Confluencia, 31/1, págs. 133-146.

\section{Trece campanadas}

González Herrán, José Manuel y Anxo Tarrío Varela (2002), «Encontro en Compostela con Xabier Villaverde e Suso de Toro», Boletín Galego de Literatura, 27, págs. 237-261.

González Herrán, José Manuel (2004), «Dos árboles de una misma semilla: Trece badaladas, de Suso Toro. Trece campanadas, de Xavier Villaverde», Ínsula, 688, págs. 27-29.

LÓPEZ LÓPEZ, Yolanda (2003), «Trece badaladas: falseando as pedras de Compostela baixo a chuvia», Madrygal, 6, págs. 69-73 [En línea: https://revistas.ucm.es/index.php/MADR/article/view/MAD R0303110069A/33281].

NúÑEZ SABARís, Xaquín (2018), «Tradición, innovación y mercado en lo fantástico en la cultura gallega: el thriller xacobeo», Brumal, 6/2, págs. 207-228 [En línea: https: //revistes.uab.cat/brumal/article/view/v6-n2nunez/pdf 47 es].

Rivero Grandoso, Javier (2012), «De Trece badaladas a Trece campanadas, ou de como dun argumento xurdiron unha novela e unha película (I)», Madrygal, 15, págs. 131-138 [En línea: 
https://revistas.ucm.es/index.php/MADR/article/view/3920 1/37798].

Rivero Grandoso, Javier (2013a), «De Trece badaladas a Trece campanadas, ou de como dun argumento xurdiron unha novela e unha película (II)», Madrygal, 16, págs. 87-93 [En línea: https://revistas.ucm.es/index.php/MADR/article/view/4299 $\underline{1 / 40796]}$.

Rivero Grandoso, Javier (2013b), «Santiago de Compostela entre o mito e a realidade en Trece badaladas/Trece campanadas», Revista de lenguas y literaturas catalana, gallega y vasca, 18, págs. 221-232 [En línea: $\quad \underline{\text { http://e- }}$ spacio.uned.es/fez/eserv.php?pid=bibliuned:Llcgv2013-187050\&dsID=Documento.pdf].

\section{Valentín}

Almela Boix, Margarita (2008), «Valentín, de Juan Gil-Albert: de la novela al teatro y al cine», en J. Romera Castillo (coord.), Teatro, novela y cine en los inicios del siglo XXI: actas del XVII Seminario Internacional del Centro de Investigación de Semiótica Literaria, Teatral y Nuevas Tecnologías, Madrid, Visor Libros, págs. 267-281.

\section{4}

\section{El año del diluvio}

Rubio Alcover, Agustín (2011), «Historicismo, historicidad: a propósito de la creación de Eduardo Mendoza con el cine español», Biblioteca on-line de ciências da comunicaçao, s.n., págs. 242 [En línea: http://bocc.ufp.pt/pag/alcover-agustinhistoricismo-historicidad.pdf].

\section{Romasanta}

Ruiz Pleguezuelos, María Rocío y Rafael Ruiz Pleguezuelos (2014), «Licantropía hispana: huellas literarias y de género en las recreaciones cinematográficas de Romasanta», en P. J. Pardo García y J. Sánchez Zapatero (coords.), Sobre la adaptación y más allá: trasvases filmoliterarios, Universidad de Salamanca, págs. 187194. 
Bibliografía sobre adaptaciones de la literatura española al cine

\section{El método}

Ferrer HammerlindL, Carlos (2012), «El teatro en el cine: el caso de Jordi Galcerán», en R. Alemany Ferrer y F.Chico Rico (eds.), XVIII Simposio de la SELGYC (Alicante 9-11 de septiembre 2010) = XVIII Simposi de la SELGYC (Alacant 9-11 setembre de 2010). Literatura i espectacle $=$ Literatura y espectáculo, Universitat d'Alacant / SELGYC, págs. 225-234 [En línea: http://www.cervantesvirtual.com/obra/el-teatro-en-el-cine-el-caso-de-jordi-galceran/].

PARÉs Pulido, Marina (2017), «De la parodia a la denuncia social: la pérdida de la ironía en la adaptación cinematográfica de El Método Grönholm», en T. López García et al. (coords.), El texto y sus fronteras: Estudios entre literaturas hispánicas y disciplinas artísticas, Madrid, Philobiblion, págs. 235-253.

Rubio Alcover, Agustín (2014), «Sin lugar en el mundo. Narrativa, puesta en escena y discurso en las películas hispanoargentinas de Marcelo Piñeyro», Fotocinema, 8, págs. 133-174 [En línea: https://revistas.uma.es/index.php/fotocinema/article/view/5 949/5453].

\section{La vida perra de Juanita Narboni}

BONNET, Véronique (2013), «La Vida perra de Juanita Narboni de Farida Benlyazid: une réécriture filmique postcoloniale?», Itinéraires, 3, págs. 81-94 [En línea: https: //journals.openedition.org/itineraires/965].

Glickman, Nora (2009), «Enajenación: La vida perra de Juanita Narboni de Ángel Vázquez, en dos adaptaciones cinematográficas», Salina, 23, págs. 165-170.

\section{Ninette}

Guarinos, Virginia (2008), «Ninette, la de un señor de Murcia, por la calle Mayor. ¿Esto era el siglo XXI? ¿o habrá que dejarle tiempo?», en J. Nicolás Romera Castillo (coord.), Teatro, novela y cine en los inicios del siglo XXI: actas del XVII Seminario Internacional del Centro de Investigación de Semiótica Literaria, Teatral y Nuevas Tecnologías, Madrid, Visor Libros, págs. 133-150.

Ríos Carratalá, Juan Antonio (2011), «La Ninette de Miguel Mihura vuelve al cine», Arbor, 187/748, págs. 317-324 [En línea: 
http://arbor.revistas.csic.es/index.php/arbor/article/view/13 $\underline{04 / 1313]}$.

\section{Obaba}

Castillo Martín, Francisca (2013), Narrativa breve y cine: técnicas de adaptación, Universidad de Málaga, págs. 225-288 [Tesis doctoral] [En línea: https://riuma.uma.es/xmlui/handle/10630/7376].

FANNINGER, Nina (2009), Vom Buch zum Film. Analyse der intermedialen Bezüge zwischen Bernardo Atxagas Obabakoak und Montxo Armendáriz Obaba unter besonderer Berücksichtigung der phantastischen Motive und Symbole, Universität Wien [Tesis doctoral].

GABIKAGOJEASKOA, Lulú (2009), «Obabakoak vs. Obaba», Letras Hispanas, 6/2, págs. 90-100 [En línea: https://gatodocs.its.txstate.edu/jcr: 85 eacc67-7d15-4c88-beaf243977a6fda4/Obabakoak.pdf].

Moreno Gómez, Carlos (2007), «Obaba (Montxo Armendáriz, 2005)», en AA.VV., Cine y habilidades para la vida. Reflexiones y nuevas experiencias de educación para la salud, cine y mass media, Gobierno de Aragón, págs. 123-151 [En línea: http://www.cineenvioleta.org/wpcontent/uploads/2014/03/Cine-y-habilidades-para-lavida.pdf\#page $=123$ ].

Orozco Vera, María Jesús (2008), «El arte de engarzar historias de Obabakoak a Obaba», en J. Nicolás Romera Castillo (coord.), Teatro, novela y cine en los inicios del siglo XXI: actas del XVII Seminario Internacional del Centro de Investigación de Semiótica Literaria, Teatral y Nuevas Tecnologías, Madrid, Visor Libros, págs. 501-514.

PIN, Irene (2018), «De Obabakoak a Obaba: a adaptación caleidoscópica», 1616, 8, págs. 167-194 [En línea: https://revistas.usal.es/index.php/1616 Anuario Literatura Comp/article/view/20729/20346].

VenKatesh, Vinodh y Virginia TECH (2012), «Perspectives, Problems, and Processes in Contemporary Spanish Adaptations», Hipertexto, 16, págs. 41-53 [En línea: https: / /www.utrgv.edu/hipertexto/ files/documents/articles /hipertexto-16/vinodh-venkatesh.pdf].

\section{Alatriste}


Bibliografía sobre adaptaciones de la literatura española al cine

Victor, Véronique (2008), "Las aventuras del capitán Alatriste" de Arturo Pérez-Reverte. Un estudio comparativo entre las novelas y la adaptación cinematográfica de Agustín Díaz Yanes, Universiteit Gent [Tesina] [En línea:

https: / libstore.ugent.be/fulltxt/RUG01/001/414/681/RUG 01-001414681 $2010 \quad 0001 \quad$ AC.pdf].

\section{Animales heridos}

Pego Puigbó, Armando (2020), «La voz híbrida y la mirada adúltera en Animals ferits (Ventura Pons, 2006)», en R. Bonilla Cerezo (ed.), Aitana Sánchez-Gijón: cintas y letras, Madrid, Sial Pigmalión, págs. 337-356.

\section{El camino de los ingleses}

PalOMar, Gregoria (2013), «El camino de los ingleses d'Antonio Soler: quand le romancier devient scénariste», Hispanística $X X, 31$, págs. 125-138.

\section{El proyecto Manhattan}

LuQue Cózar, Ramón y Juan José Domínguez LóPEZ (2009), «El proyecto Manhattan, un ejemplo de producción desde la universidad», en J. J. Marzal Felici y F. J. Gómez Tarín (coords.), El productor y la producción en la industria cinematográfica, Madrid, Editorial Complutense, págs. 465-480.

LuQue CÓZAR, Ramón y Juan José DOMínguez LóPEZ (2012), «Cine y universidad: una experiencia desde el mundo estético de Woody Allen», Comunicación 21, 2 [En línea: http://www.comunicacion21.com/cine-y-universidad-unaexperiencia-desde-el-mundo-estetico-de-woody-allen-2/].

\section{Honor de cavalleria}

Castillo Peña, Carmen y José Pérez Navarro (2007), De texto a texto: traducción, adaptación, reescritura, Padova, Unipress.

GonzÁlez de CANales CARCERENY, Júlia (2017), «El cine de Albert Serra: apropiación y reinterpretación fílmica de los clásicos literarios», Fotocinema, 14, págs. 83-98 [En línea: https://revistas.uma.es/index.php/fotocinema/article/view/3 573/3311]. 
GonzÁlez de Canales Carcereny, Júlia (2018), «Albert Serra. Para un cine de artificio y naturalismo», L'Atalante, 26, págs. 111-122 [En

http://www.revistaatalante.com/index.php?journal=atalante\& page $=$ article\&op $=$ view $\&$ path $\% 5 \mathrm{~B} \% 5 \mathrm{D}=661 \&$ path $\% 5 \mathrm{~B} \% 5 \mathrm{D}=4$ 91].

LÓPEZ LÓPEZ, Yolanda (2017), El Siglo de Oro en el cine y la ficción televisiva: Dirección artística, referentes culturales y reconstrucción histórica, Madrid, ACCI, págs. 126-151.

MUÑOZ FERNÁNDEZ, Horacio (2015), «Estéticas románticas en el cine de Albert Serra», en E. Camarero y M. Marcos (coords.), III Congreso Internacional de Histora, Literatura y Arte en el Cine en español y portugués. Hibridaciones, transformaciones y nuevos espacios narrativos. II, Salamanca, Hergar Ediciones Antema, págs. 10-20 [En línea: https: //congresocinesalamanca2015.files.wordpress.com/2016 105/salamanca-actas-tomo-2.pdf].

NeIra PiÑeIro, María del Rosario (2008), «El Quijote en su transposición al medio cinematográfico: problemas de la adaptación», en M. Á. Garrido Gallardo y L. Alburquerque García (coords.), El Quijote y el pensamiento teórico-literario, Madrid, CSIC, págs. 399-406.

Palladino, Nicola (2018), «Honor de Cavalleria, riflessioni sul Quijote di Albert Serra», Rassegna iberistica, 41/109, págs. 145-155 [En línea:

https://edizionicafoscari.unive.it/media/pdf/journals/rassegna -iberistica/2018/109/iss-41-109-2018 zJzfqAg.pdf].

ReINSTÄDLER, Janett (2019), «Los sueños de Don Quijote en el cine: dinámicas transmediales», Ibero, 90, págs. 151-171.

Stadelmaier, Philipp (2014), «Unterwegs. Zum Kino von Albert Serra», Zeitschrift für Katalanistik, 27, págs. 127-141 [En línea: http://www.romanistik.unifreiburg.de/pusch/zfk/27/12 Stadelmaier.pdf].

TALENS, Jenaro (2011), «Honor de caballería: una relectura fílmica del Quijote», Letra internacional, 110, págs. 56-61.

TALENS, Jenaro (2020), «Deconstructing narrativity on the screen: Re-reading Don Quixote in Albert Serra's Honor de cavalleria (Spain, 2006)», Eu-topías, 20, págs. 7-16 [En línea: https://ojs.uv.es/index.php/eutopias/article/view/19385/17 111].

\section{La dama boba}


Bibliografía sobre adaptaciones de la literatura española al cine

Berger, Verena (2009), «El teatro del Siglo de Oro y el cine español: La dama boba (2006) de Manuel Iborra», en V. Berger y M. Saumell (eds.), Escenarios compartidos: Cine y teatro en España en el umbral del siglo XXI, Wien/Berlín, Lit Verlag, págs. 60-74.

LÓPEZ LóPeZ, Yolanda (2017), El Siglo de Oro en el cine y la ficción televisiva: Dirección artística, referentes culturales y reconstrucción histórica, Madrid, ACCI, págs. 219-229.

MalPartida TiRAdO, Rafael (2018), «El componente verbal en las adaptaciones de la literatura áurea española al cine y la televisión: una propuesta de estudio», Edad de Oro, XXXVII, págs. 184-227 [En línea: https: / /revistas.uam.es/edadoro/article/view/10288/10449].

TRECCA, Simone (2011), «La adaptación fílmica de La dama boba», en A. Azaustre Galiana y S. Fernández Mosquera (coords.), Compostella aurea. Actas del VIII Congreso de la Asociación Internacional del Siglo de Oro. III, Universidad de Santiago, págs. 467-475.

\section{Las locuras de Don Quijote}

Castillo Peña, Carmen y José Pérez Navarro (2007), De texto a texto: traducción, adaptación, reescritura, Padova, Unipress.

\section{Tirant lo Blanc}

Alemany Ferrer, Rafael (2009), «La reescritura fílmica del Tirant to Blanc de Vicente Aranda», en J. L. Martos Sánchez y M. García Sempere (eds.), L'edat mitjana en el cinema i en la novel-la històrica, Alicante, Institut Interuniversitari de Filologia Valenciana, págs. 11-35 [En línea: https://rua.ua.es/dspace/bitstream/10045/12138/2/TIRANT ARANDA.pdf].

AlemAny Ferrer, Rafael (2011), «El desenllaç de l'adaptació cinematogràfica del Tirant lo Blanc de Vicente Aranda en relació amb l'original de Joanot Martorell: repercussions estètiques i conceptuals», en J. Veny Clar et al. (eds.), Actes del Quinzè Col·loqui Internacional de Llengua i Literatura Catalanes: Universitat de Lleida, 7 11 de setembre de 2009. Volum. II, Barcelona, Abadia de Montserrat, págs. $\quad 359-370 \quad$ [En línea: https://rua.ua.es/dspace/bitstream/10045/17356/3/27 alem any rafael.pdf]. 
Ferrando Morales, Àngel Lluís (2016), L'element musical de l'adaptació cinamatogràfica del "Tirant lo Blanc" de Vicente Aranda (2006), Universidad de Alicante.

PÉREZ BOWIE, José Antonio (2008), «La adaptación como reescritura. Algunos ejemplos de la filmografía de Vicente Aranda», en A. Notario Ruiz y J. L. Molinuevo Martínez (eds.), Estética: Perspectivas contemporáneas, Universidad de Salamanca, págs. 6788.

\section{Salvador (Puig Antich)}

FERNÀNDEZ, Josep-Anton (2014), «Hero, Martyr, or Saint? Rewriting Anti-Franco Resistance in Manuel Huerga's Salvador», Zeitschrift für Katalanistik, 27, págs. 85-100 [http://www.romanistik.unifreiburg.de/pusch/zfk/27/09 Fernandez.pdf].

\section{7}

\section{Bajo las estrellas}

García Reina, María del Mar (2015), «El trompetista del Utopía de Fernando Aramburu», en E. Camarero y M. Marcos (coords.), III Congreso Internacional de Historia, Literatura y Arte en el Cine en español y portugués. Hibridaciones, transformaciones y nuevos espacios narrativos. I, Salamanca, Hergar Ediciones Antema, págs. 690-702 [En línea: https: //congresocinesalamanca2015. files. wordpress.com/2016 105/salamanca-actas-tomo-1.pdf].

\section{Barcelona (un mapa)}

FERNÁNDEZ, Josep-Anton (2012), «Translating the Enigma: Temporality and Subjectivity in Ventura Pons's Barcelona (Un mapa)», en H. Buffery y C. Caulfield (eds.), Barcelona: Visual Culture, Space and Power, Cardiff, University of Wales Press, págs. 119-132.

Gimeno UGalde, Esther (2014), «Un cine con acento: Polifonía, multilingüismo y alteridad en el cine de Ventura Pons», Zeitschrift für Katalanistik, 27, págs. 69-84 [En línea: http://www.romanistik.unifreiburg.de/pusch/zfk/27/08 Gimeno-Ugalde 2.pdf].

\section{Canciones de amor en Lolita's Club}


Bibliografía sobre adaptaciones de la literatura española al cine

PÉREZ BowIE, José Antonio (2008), «La adaptación como reescritura. Algunos ejemplos de la filmografía de Vicente Aranda», en A. Notari Ruiz (ed.), Estética: Perspectivas contemporáneas, Universidad de Salamanca, págs. 67-88.

\section{Donkey Xote}

ABRIL SÁNCHEZ, Jorge (2016), «Don Quixote de la Mancha and Spanish Children Animation and Cartoons: Miguel de Cervantes's Uses of Bestial Enchantment for Young Readers and Viewers in the 2000s», en C. García de la Rasilla y J. Abril Sánchez (eds.), A Novel Without Boundaries: Sensing "Don Quixote" 400 Years Later, Newark, Juan de la Cuesta, págs. 51-73.

Bonilla Cerezo, Rafael (2015), «Un Quijote de cine para niños grandes: Donkey Xote (José Pozo, 2007)», Anales cervantinos, 47, págs. [En 47-132 línea: http://analescervantinos.revistas.csic.es/index.php/analescerva ntinos/article/view/268/269].

España, Rafael de (2007), De la Mancha a la pantalla. Aventuras cinematográficas del Ingenioso Hidalgo, Universidad de Barcelona.

LORENZO García, Lourdes y Beatriz María RodríGuEz RodríGueZ (2015), «La intertextualidad en los textos audiovisuales: el caso de Donkey Xote», Ocnos, 13, págs. 117-128 [En línea: https://www.revista.uclm.es/index.php/ocnos/article/view/o cnos 2015.13.07/pdf].

SCAmuZZI, Iole (2018), «Donkey Xote: cervantismo en 3D», en B. Lolo Herranz (coord.), "El Quijote” y la música en la construcción de la cultura europea, Universidad Autónoma de Madrid, págs. 765-774.

\section{La carta esférica}

Molero Campos, Fernando (2020), «Unas esmeraldas son para siempre: La carta esférica (Arturo Pérez-Reverte, 2000 / Imanol Uribe, 2007)», en R. Bonilla Cerezo (ed.), Aitana Sánchez-Gijón: cintas y letras, Madrid, Sial Pigmalión, págs. 377-405.

\section{Las 13 rosas}

Guarinos, Virginia (2008), «Ramos de Rosas Rojas. Las trece rosas: memoria audiovisual y género», Quaderns de cine, 3, págs. 91-103 [En

línea: 
https://idus.us.es/bitstream/handle/11441/28341/ramos-derosas-rojas-las-trece-rosas-memorial-audiovisual-y-gnero0 .pdf?sequence $=1$ ] .

\section{Luz de domingo}

Friera SuÁreZ, Florencio (2007), «Luz de domingo: de Pérez de Ayala a José Luis Garci», en AA. VV., Primer tercio del siglo XX: Noreña en tiempos de Pérez de Ayala, Noreña, Contigo, págs. 9-15.

SÁncheZ Costa, Enrique (2009), «Luz de domingo: texto literario y adaptación fílmica», Frame, 5, págs. 55-68.

SÁNCHEZ COSTA, Enrique (2012), «Luz de domingo: texto literario y adaptación fílmica», Tropelías, 18, págs. 326-339 [En línea: https://papiro.unizar.es/ojs/index.php/tropelias/article/view $1562]$.

\section{8}

\section{Forasteros (Forasters)}

Gimeno Ugalde, Esther (2014), «Un cine con acento: Polifonía, multilingüismo y alteridad en el cine de Ventura Pons», Zeitschrift für Katalanistik, 27, págs. 69-84 [En línea: http://www.romanistik.unifreiburg.de/pusch/zfk/27/08 Gimeno-Ugalde 2.pdf].

Marcillas Piquer, Isabel (2013), «De Sergi Belbel a Ventura Pons: l'estètica transmedial de Forasters», L'Aiguadoç, 41, págs. 47-60 [En https://rua.ua.es/dspace/bitstream/10045/38038/1/De\%20B elbel $\% 20 \mathrm{a} \% 20$ Pons.pdf].

\section{Los girasoles ciegos}

Castillo Martín, Francisca (2013), Narrativa breve y cine: técnicas de adaptación, Universidad de Málaga, págs. 289-362 [Tesis doctoral] [En línea: https: //riuma.uma.es/xmlui/handle/10630/7376].

CRESPO ViLA, Raquel (2013), «La adaptación cinematográfica de Los girasoles ciegos: de la letra de Alberto Méndez a la imagen de José Luis Cuerda», en E. Camarero y M. Marcos (coords.), II Congreso Internacional de Histora, Literatura y Arte en el Cine en Español y Portugués. De los orígenes a la revolución tecnológica del siglo XXI. Actas completas, Salamanca, Hergar Ediciones Antema, págs. 284-292 [https://cebusal.es/publicacion ceb/ii-congreso-internacional- 
Bibliografía sobre adaptaciones de la literatura española al cine

de-historia-literatura-y-arte-en-el-cine-en-espanol-y-portuguesde-los-origenes-a-la-revolucion-tecnologica-del-siglo-xxi-actascompletas/].

DevenY, Thomas (2012), «Los girasoles ciegos: la memoria de la represión», en B. Zecchi (ed.), Teoría y práctica de la adaptación filmica, Madrid, Universidad Complutense, págs. 255-270.

HAFTER, Lea Evely (2009), «Literatura y cine: convergencias en la narrativa española contemporánea. Una lectura de Los girasoles ciegos, de Alberto Méndez», en M. Genoud de Fourcade (ed.), Unidad y multiplicidad. Tramas del hispanismo actual. II, Mendoza, Zeta Editores, págs. 258-264.

LÓPEZ LÓPEZ, Yolanda (2020), «Girasoles y mariposas. Apuntes sobre represión franquista en el cine de José Luis Cuerda», en M. de la Encarnación Cambil Hernández et al. (coords.), Nuevas tendencias en investigación e innovación en didáctica de la historia, patrimonio cultural y memoria. Proyección educativa, Universidad de Granada, págs. 621-638.

PÉREZ, Soledad (2011), «QQué pasa, mamá? La representación de la infancia de la post-guerra civil española en Los girasoles ciegos (relato y película)», en R. Macciuci (ed.), Diálogos transatlánticos. Memoria del II Congreso Internacional de Literatura y Cultura Española Contemporáneas. Volumen III: Literatura, arte, cine, otros medios: diálogos, cruces y convergencias [En línea: http://www.memoria.fahce.unlp.edu.ar/trab eventos/ev. 282 5/ev.2825.pdf].

Ramos, María Laura (2011), «Mirada, reflejo y ocultamiento en Los girasoles ciegos», en R. Macciuci (ed.), Diálogos transatlánticos. Memoria del II Congreso Internacional de Literatura y Cultura Española Contemporáneas. Volumen III: Literatura, arte, cine, otros medios: diálogos, cruces y convergencias [En línea: https: //www. aacademica.org/000-042/91.pdf].

Ríos Carratalá, Juan Antonio (2008), «El último guión de Rafael Azcona», I Congreso Internacional de Literatura y Cultura Españolas Contemporáneas, 1 al 3 de octubre de 2008, La Plata. Los siglos XX y $X X I \quad$ [En línea: http://www.memoria.fahce.unlp.edu.ar/trab eventos/ev. 357 /ev.357.pdf].

Ruiz MartíneZ, José Manuel (2015), «La memoria adaptada al cine. El caso de Los girasoles ciegos», en J. C. Cruz Suárez et al. (eds.), La memoria novelada III. Memoria transnacional y anhelos de justicia, Berna, Peter Lang, págs. 263-278. 
SERBER, Daniela Cecilia (2011), «Al otro lado del espejo y lo que Lorenzo encontró allí: sobre la palabra y el silencio en Los girasoles ciegos, de Alberto Méndez y de Cuerda-Azcona», en R. Macciuci (ed.), Diálogos transatlánticos. Memoria del II Congreso Internacional de Literatura y Cultura Española Contemporáneas. Volumen III: Literatura, arte, cine, otros medios: diálogos, cruces y convergencias [En línea: http://congresoespanyola.fahce.unlp.edu.ar/ii-congreso2011/actas-ii-2011/volumen-iii/III10Serber.pdf].

\section{Sangre de mayo}

NAVARRETE-Galiano RodrígueZ, Ramón (2012), «Nuevas traducciones de Galdós. Adaptaciones de los Episodios nacionales», Revista de Humanidades, 19, págs. 11-23 [En línea: http://revistas.uned.es/index.php/rdh/article/view/12830/1 1939].

Navarrete-Galiano Rodríguez, Ramón (2009), «Sangre de Mayo. Una traducción galdosiana», Historia y Comunicación Social, 14, págs. $\quad 45-56 \quad$ [En línea: https: //idus.us.es/bitstream/handle/11441/29257/1967019710-1-PB.PDF?sequence $=1$ \&isAllowed $=\mathrm{y}$ ].

\section{Una palabra tuya}

GARCÍA MÉRIDA, Marina (2019), «Entrevista a Elvira Lindo», Trasvases entre la literatura y el cine, 1, págs. 209-216 [En línea: [https: //revistas.uma.es/index.php/trasvases/article/view/667 8/6906].

García MÉRIDA, Marina (2020), La obra narrativa de Elvira Lindo y sus adaptaciones al cine, Universidad de Málaga, págs. 597-796 [Tesis doctoral] [En línea: https://riuma.uma.es/xmlui/handle/10630/21084].

\section{9}

\section{Celda 211}

Arroyo Martínez, Laura (2011), «Celda 211: la adaptación cinematográfica de Daniel Monzón», en E. Camarero Calandria y M. Marcos Ramos (coords.), I Congreso Internacional de Historia, 
Bibliografía sobre adaptaciones de la literatura española al cine

Literatura y Arte en el Cine en Español y Portugués, Salamanca, Centro de Estudios Brasileños/Universidad de Salamanca, págs. 16161631 .

\section{El cónsul de Sodoma}

MIRA, Alberto (2011), «Poetas en el cine: paradigmas teóricos en dos narrativas biográficas (Little Ashes y El cónsul de Sodoma)», Lectora, 17, págs. 123-138 [En línea: https: //revistes.ub.edu/index.php/lectora/article/view/7210 19114].

SÁNCHEZ ZAPATERO, Javier (2019), «Escritores en la gran pantalla: el biopic literario en el cine español contemporáneo», en $\mathrm{R}$. Previtera (ed.), El ojo que escribe (Estudios sobre las relaciones entre cine y literatura), Málaga, EDA, págs. 129-145.

SÁNCHEZ ZAPATERO, Javier (2020), «Retrato de poeta: vida y literatura de Jaime Gil de Biedma en El cónsul de Sodoma», 1616, 10, págs. $\quad 59-70 \quad$ [En línea: https://revistas.usal.es/index.php/1616 Anuario Literatura Comp/article/view/25319/24709].

\section{0}

\section{Elisa $K$}

IGLESIAS, Eulàlia (2010), «Rodar juntos pero no revueltos. Jordi Cadena y Judith Colell adaptan a Lolita Bosch en Elisa K», Cahiers du cinéma, 32, págs. 56-57.

\section{Pan negro (Pa negre)}

Andres del Pozo, Natalia (2011), «Pa negre: Lobos con piel de cordero o la expulsión de una Arcadia soñada», Hispanet, 4 [En línea: http://www.hispanetjournal.com/PaNegre.pdf].

Arroyo MartíneZ, Laura (2013), «Pan negro: de la narrativa de Emili Teixidor a la película de Agustí Villaronga», en Á. Luis Hueso Montón y M. Gloria Camarero Gómez (coords.), III Congreso Internacional de Historia y Cine. Modelos de interpretación para el cine histórico, Universidade de Santiago de Compostela, pág. 55.

GLENN, Kathleen M. (2012), «From Page to Screen: Emili Teixidor's and Agustí Villaronga's Pa negre», Journal of Catalan Studie, 15, págs. 52-68. 
Mabrey, María Cristina C. (2015), «Pasado y presente, guerra, odio y amor: una mirada feminista a Pa negre (Pan negro), de Agustí Villaronga», en M. Emma Camarero Calandria y M. Marcos Ramos, III Congreso Internacional de Histora, Literatura y Arte en el Cine en español y portugués. Hibridaciones, transformaciones y nuevos espacios narrativos. II, Salamanca, Hergar Ediciones Antema, págs. 293-302

[En

línea:

https://congresocinesalamanca2015.files.wordpress.com/2016 /05/salamanca-actas-tomo-2.pdf].

Moreiras-MenOR, Cristina (2018), «La mirada traidora y el saber del síntoma: Pa negre en texto y en imagen», Revista de Estudios Hispánicos, 52/2, págs. 433-454.

2011

\section{La voz dormida}

Delgado Poust, Antonia (2019), «Cómplices de la opresión: la enemistad femenina y la conspiración con el patriarcado en $\mathrm{La} \mathrm{voz}$ dormida», en M. Marcos Ramos (ed.), El cine como reflejo de la historia, de la literatura y del arte en la filmografía hispano-brasileña, Salamanca, Centro de Estudios Brasileños, págs. 32-52.

Gruber, Mónica (2020), «Reflexiones sobre la construcción de la imagen femenina. La voz dormida: de Dulce Chacón a Benito Zambrano», Cuadernos del Centro de Estudios de Diseño y Comunicación. Ensayos, 95, págs. 81-96 [En línea: https: / fido.palermo.edu/servicios dyc/publicacionesdc/cuade $\underline{\mathrm{rnos} / \text { detalle articulo.php?id libro }=778 \& \mathrm{id} \text { articulo }=16218 \mathrm{]}}$.

JAÉN PORTILLO, Isabel (2016), Aspectos cognitivos entorno a la novela y el cine de la memora histórica: La voz dormida de Dulce Chacón y su adaptación fílmica, Universidad Complutense de Madrid [Tesis doctoral] [En línea: https://eprints.ucm.es/id/eprint/40032/1/T37987.pdf].

JaÉN PORTILlO, Isabel (2017), «Fascism, Torture, and Affect in Postwar Spain: Memoria Histórica Narratives and Audience Empathy», en D. R. Wehrs y T. Blake (eds.), The Palgrave Handbook of Affect Studies and Textual Criticism, Cham, Springer International Publishing, págs. 803-826.

Ugarte, Michael (2017), «Dead Woman Walking. "Historical Memory", Trauma, and Adaptation in Dulce Chacón's La voz dormida», en M. Bieder y R. Johnson (eds.), Spanish Women Writers and Spain's Civil War, Nueva York, Routledge, págs. 221-234. 
Bibliografía sobre adaptaciones de la literatura española al cine

\section{Arrugas}

Abad Vila, Miguel y María Blanca Mayor Serrano (2019), «Arrugas (2011) de Ignacio Ferreras. La enfermedad de Alzheimer a través del cómic y del cine», Revista de medicina y cine, 15/4, págs. 237 247 [En línea:

https://revistas.usal.es/index.php/medicina y cine/article/vi ew/rmc2019154237247/21284].

FERnÁNDEZ RodrígueZ, María (2019), «La adaptación. ¿Fiel al cien por cien? El caso de Arrugas de Paco Roca», en M. Marcos Ramos (ed.), El cine como reflejo de la historia, de la literatura y del arte en la filmografía hispano-brasileña, Salamanca, Centro de Estudios Brasileños, págs. 353-364.

GiL Rumí, Sonia (2016), «Arrugas (2007), de Paco Roca: la adaptación cinematográfica», en J. Lluch-Prats et al. (coords.), Las batallas del cómic. Perspectivas sobre la narrativa gráfica contemporánea, Valencia, Anejos de Diablotexto Digital, págs. 133-149 [En línea: https://www.uv.es/diabltxd/Anejo1DTD.pdf].

RocA, Paco (2013), «De la viñeta al fotograma», Archivo de arte valenciano, 94, págs. 343-350 [HTTPS://roderic.uv.es/bitstream/handle/10550/74405/4718 831.pdf?sequence $=1$ \&isAllowed $=\mathrm{y}]$.

Ramírez GómEZ, David (2019), «El cine español adapta y se adapta al cómic», en M. Marcos Ramos (ed.), El cine como reflejo de la historia, de la literatura y del arte en la filmografía hispano-brasileña, Salamanca, Centro de Estudios Brasileños, págs. 234-247.

\section{Mil cretinos (Mil cretins)}

PÁmies, Susanna P. (2015), «La reescritura visual de Quim Monzó según Mil cretins (2010) de Ventura Pons», en C. Domènech y A. Lema Hicapié (eds.), Ventura Pons: una mirada excepcional desde el cine catalán, Madrid, Iberoamericana, pág. 259-272.

Silvestre Llinares, Jaume (2013), «Els contes de Quim Monzó vistos per Ventura Pons: a propòsit de Mil Cretins», Aiguadolç, 41, págs. 27-35

[https: / /www.raco.cat/index.php/Aiguadolc/article/view/27 4043/373573].

\section{Silencio en la nieve}


VISCARRI, Dionisio (2015), «Silencio en la nieve y la rehistorización de la experiencia divisionaria», España contemporánea, 24/25, págs. 243-260 [En línea: https://kb.osu.edu/bitstream/handle/1811/77802/EC V24N 2 V25N1-2 243.pdf].

\section{2}

Fin

Morillo Herrero, Lucía (2018), «La recepción popular de la literatura y el cine apocalípticos en España: Fin y Extinction», en R. Malpartida Tirado (coord.), Recepción y canon de la literatura española en el cine, Madrid, Síntesis, págs. 57-79.

\section{3}

\section{El lazarillo de Tormes}

BobADILlA-PÉREZ, María (2021), «Adaptación infantil del Lazarillo de Tormes», en A. Rodríguez López-Vázquez y A. Rodríguez LópezAbadía (eds.), El Lazarillo de Tormes y sus continuadores, Berna, Peter Lang, págs. 267-282.

Ibarluzea Santisteban, Miren y Amaia Elizalde Estenaga (2019), «El Lazarillo en Euskera», en P. Couto-Cantero et al. (eds.), Actas del Simposio del Lazarillo, Universidade da Coruña, págs. 61-68 [En línea:

https: / /ruc.udc.es/dspace/bitstream/handle/2183/27517/Sim posio El\%20Lazarillo\%20y\%20sus\%20continuadores 2019 A \%20Coru\%c3\%b1a Comunicaci\%c3\%b3n\%205 \%20Ibarluzea \%20Santisteban_Miren_El\%20Lazarillo\%20en\%20euskera.pdf?s equence $=3 \&$ is Allowed $=\mathrm{y}$.

Junguitu Dronda, Maitane (2019), «Tormesko itsumutila», en Kalabaza Planeta eta Juanba Berasategi. Panorámica de la animación comercial vasca, Universidad del País Vasco, págs. 379-399 [Tesis doctoral] [En línea: https: / / addi.ehu.eus/bitstream/handle/10810/45071/TESIS_J UNGUITU DRONDA MAITANE.pdf?sequence $=1$ \&isAllowed $\equiv \mathrm{y}]$.

El club de los incomprendidos 
Bibliografía sobre adaptaciones de la literatura española al cine

García MÉRIDA, Marina (2020), «El Club de los Incomprendidos (Blue Jeans / Carlos Sedes, 2014)», en R. Bonilla Cerezo (ed.), Aitana Sánchez-Gijón: cintas y letras, Madrid, Sial Pigmalión, págs. 691689.

\section{A esmorga}

SÁNCheZ González, Darío (2020), «Social Danger and Queer Nationalism in Ignacio Vilar's $A$ esmorga (2014)», en A. LemaHincapié y C. Domènech (eds.), Indiscreet Fantasies: Iberian Queer Cinema, Lewisburg, Bucknell University.

\section{5}

\section{Extinction}

Morillo Herrero, Lucía (2018), «La recepción popular de la literatura y el cine apocalípticos en España: Fin y Extinction», en R. Malpartida Tirado (coord.), Recepción y canon de la literatura española en el cine, Madrid, Síntesis, págs. 57-79.

\section{Palmeras en la nieve}

Álvarez Chiluida, Gonzalo (2016), «Palmeras en la nieve. El éxito de la colonización española en Guinea Ecuatorial», Spagna contemporanea, 50, págs. 251-263 [En línea: https://www.spagnacontemporanea.it/index.php/spacon/artic le/view/143/74].

Santamaría Colmenero, Sara (2018), «Colonizar la memoria. La ideología de la reconciliación y el discurso neocolonial sobre Guinea Ecuatorial», Journal of Spanish Cultural Studies, 19/4, págs. $445-463$.

\section{La novia}

Abellán Chuecos, Isabel (2017), «Las cuerdas y el deseo: dos versiones de Bodas de sangre de Federico García Lorca», Cuadernos del Aleph, 9, págs. 1-9 [En línea: http://www.asociacionaleph.com/images/CuadernosDeAleph/ 2017/01.pdf].

AlCALDE, Verónica (2019), «La translación de un clásico literario a la pantalla: Bodas de sangre y La novia, entre la fidelidad y la traición», Boletín GEC, 24, págs. 24-64 [En línea: 
http://revistas.uncu.edu.ar/ojs3/index.php/boletingec/article /view/2287/1923].

Campo Marco, Lara (2017), «La Novia, de Paula Ortiz: Lorca y Bodas de sangre hechos cine», en M. Marcos Ramos (ed.), IV Congreso Internacional Historia, arte y literatura en el cine en español y portugués: studios y perspectivas, Salamanca, Centro de Estudios Brasileños, págs. [En 607-626 línea: https://cebusal.es/publicacion ceb/historia-literatura-y-arteen-el-cine-en-espanol-y-portugues-estudios-y-perspectivas-2/].

Campo Marco, Lara (2018), «La Novia, de Paula Ortiz: Lorca y Bodas de sangre hechos cine», en A. Asión Suñer et al. (coords.), La historia del Arte desde Aragón, Universidad de Zaragoza, págs. $243-$ 254.

Gil-Albarellos Pérez-Pedrero, Susana (2018), «Bodas de sangre y La novia: de Federico García Lorca a Paula Ortiz», Tonos digital, 35 [En línea: https: / / digitum.um.es/digitum/bitstream/10201/60482/1/1 999-5679-1-PB.pdf].

SEOANe Riveira, José (2018), «Una reescritura cinematográfica del teatro lorquiano: La novia, de Paula Ortiz», en J. Antonio Pérez Bowie, La teatralidad en la pantalla: reflexiones sobre el diálogo contemporáneo entre cine y teatro, Madrid, Catarata, págs. 149-181.

Vilanova NAVALÓn, Estefanía (2018), La adaptación cinematográfica del teatro: análisis comparativo de "La novia" de Paula Ortiz (2015), Universidad de Alicante [Trabajo de Fin de Máster] [En línea: https://rua.ua.es/dspace/bitstream/10045/75949/1/TFMEstefania-Vilanova.pdf].

\section{La playa de los ahogados}

SÁNCHEZ ZAPATERO, Enrique (2017), «La playa de los ahogados: el paso de la novela al cine», en J. Sánchez Zapatero y À. Martín Escribà (coords.), La globalización del crimen: literatura, cine y nuevos medios, Santiago de Compostela, Andavira, págs. 435-441.

\section{6}

\section{El hombre de las mil caras}

DiEz PUERTAS, Emeterio (2019), «Relato de integridad y corrupción», Cuadernos Hispanoamericanos, 834, págs. 57-71 [En línea: 
Bibliografía sobre adaptaciones de la literatura española al cine

https: //cuadernoshispanoamericanos.com/relato-de-integridady-corrupcion].

\section{La punta del iceberg}

Rivero Grandoso, Javier (2019), «El proceso de adaptación de $L a$ punta del iceberg: texto dramático, representaciones y película», en A. Saura Clares e I. Guerrero (coords.), Estudios teatrales: nuevas perspectivas y visiones comparadas, Universidad de Murcia, págs. 225 234.

\section{2 ángeles (TV)}

GutiÉRREZ FONSECA, Itza Nahomy (2020), «Los serafines de la viruela: 22 ángeles (2016)», Manifestaciones sociales y artísticas, 16, págs. 369-378 [En línea: https://revistas.usal.es/index.php/medicina y cine/article/vi ew/rmc202016e369378/25338].

\section{7}

\section{La piel fría (Cold Skin)}

ILLESCAS, Raúl M. (2020), «La otredad en la literatura y el cine. La piel fría, de Albert Sánchez Piñol y el film Cold Skin de Xavier Gens», Polifonía, 10/1, págs. 150-171 [En línea: https://www.apsu.edu/polifonia/volume 10/2020 10 Illesca s.pdf].

\section{Incierta gloria (Incerta glòria)}

EsPINÓs, Joaquim (2019), «Agustí Villaronga: una mirada heterodoxa sobre la Guerra Civil», eHumanista/IVITRA, 15, págs. 478-485 [En línea:

https://rua.ua.es/dspace/bitstream/10045/93389/1/2019 Es pinos eHumanista-IVITRA.pdf].

\section{El jugador de ajedrez}

LOTFI, Berbar (2021), Adaptación cinematográfica de la novela El jugador de ajedrez de Julio Castedo: Estudio comparado, Universidad Abou Bekr Belkaid de Tlemcen [Tesis doctoral] [En línea: 
http: //dspace.univ-

tlemcen.dz/bitstream/112/16252/1/berbar-lotfi.pdf].

\section{8}

\section{Tiempo después}

Herrera Herrera, María del Carmen (2019), «Imaginar el futuro entre distopía y desengaño: Tiempo después de José Luis Cuerda», en M. Marcos Ramos (ed.), El cine como reflejo de la historia, de la literatura y del arte en la filmografía hispano-brasileña, Salamanca, Centro de Estudios Brasileños, págs. 341-352.

\section{9}

\section{Intemperie}

ARbona AbASCAL, Guadalupe (2019), «Intemperie de Jesús Carrasco. La transmisión de una novela en la era global», Tonos Digital, 36 [En línea: http://www.tonosdigital.es/ojs/index.php/tonos/article/view

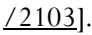

BeRnal, Fernando (2019), «Dentro de la prosa áspera: Intemperie, de Benito Zambrano», Caimán, 87, pág. 54.

Ruiz MuÑoz, María Jesús et al. (2020), «La Guerra Civil española y sus consecuencias: representaciones de la represión en la infancia a través de la cinematografía (2000-2019)», Historia y comunicación social, 25/2, págs. 345-354 [En línea: https: / / revistas.ucm.es/index.php/HICS/article/view/70384/ 4564456554954]. 
Bibliografía sobre adaptaciones de la literatura española al cine

\title{
Apéndice
}

\section{Películas que aún no han sido estudiadas como adaptaciones de la literatura al cine \\ (2001-2020)}

\author{
A la deriva \\ A la sombra de los sueños \\ ¿A quién te llevarías a una isla desierta? \\ Acantilado \\ Alacrán enamorado \\ Amor idiota \\ Ánimas \\ Asamblea \\ Atlas de geografía humana \\ $B$ de Bárcenas \\ Bendita calamidad \\ Bendito Canalla, la verdadera historia de Genarín \\ Bernarda \\ Besos de gato \\ Black is Beltza \\ Born \\ Buñuel en el laberinto de las tortugas \\ Campanadas a muerto (Hil Kanpaiak) \\ Casi inocentes \\ Castillos de cartón \\ Cenizas (La pols) \\ Desde el Infierno \\ Diario de una becaria \\ Diario de una ninfómana \\ Dioses y perros \\ Don Mendo Rock. ¿La venganza? \\ Donde el bosque se espesa \\ Dos hermanos (Bi anai) \\ El año de la plaga \\ El autor \\ El aviso \\ El corazón de la Tierra \\ El crédito (El crèdit) (TV) \\ El discípulo
}


El extraordinario viaje de Lucius Dumb (Lucius Dumben berebiziko bidaia)

El florido pensil

El guardián invisible

El hijo del acordeonista (Soinujolearen seme)

El idioma imposible

El inconveniente

El juego del ahorcado

El libro de las aguas

El mal del arriero

El método Grönholm (TV)

El miedo (La por)

El misterio Galíndez

El país del miedo

El paraíso ya no es lo que era

El plan

El rey

El rey tuerto (E1 rei borni)

El silencio de la ciudad blanca

El silencio del pantano

El triunfo

El viaje de Carol

El virus del miedo (E1 virus de la por)

Elisa y Marcela

Enjambre (Erlauntza)

Enséñame el camino, Isabel (Kutsidazu bidea, Ixabel)

Eroski Paraíso

Errementari (El herrero y el diablo)

Gente que viene y bah

Hijo de Caín

Hipnos

Hormigas en la boca

Invasor

Isaac

La estación violenta ( $A$ estación violenta)

La estrategia del pequinés

La estrella

La higuera de los bastardos

La llamada

La mano invisible

La mujer del siglo (La dona del segle) (TV)

La mula

La niebla y la doncella 
Bibliografía sobre adaptaciones de la literatura española al cine

La revolución de los ángeles

La soledad del triunfo (TV)

La soledad era esto

La tarara del chapao

La venta del paraíso

La vida abismal

La vida en rojo

La vida sin Sara Amat (La vida sense la Sara Amat)

Laia (TV)

Las aventuras de Don Quijote

Las heridas del viento

Las manos de mi madre (Amaren eskuak)

Las manos del pianista (TV)

Legado en los huesos

Les nenes no haurien de jugar a futbol (TV)

Litus

Llueven vacas

Lo mejor que le puede pasar a un cruasán

Los aires difíciles

Los europeos

Los futbolísimos

Los habitantes de la casa deshabitada (TV)

Los muertos no se tocan, nene

Los novios búlgaros

Malnazidos

Memorias de un hombre en pijama

M'esperaràs?

Miau

Muertos de amor

Musa

Ni pies ni cabeza

No culpes al karma de lo que te pasa por gilipollas

No te supe perder

Nos miran

Nur y el Templo del Dragón (Nur eta herensugearen tenplua)

Ofrenda a la tormenta

Orígenes secretos

Oro

Pacto de Brujas

Planta $4^{a}$

Por un puñado de besos

Presentimientos 


\section{Manuel España Arjona}

Primer y último amor

Radiacions (TV)

Rastros de sándalo (Rastres de sàndal)

Rottweiler

Segundo origen (Segon origen)

Sentimental

Sinbad

Sordo

Tánger

Tierra firme (Anchor and Hope)

Todo es silencio

Todo me pasa a mi

Tu vida en 65 minutos

Un día perfecto (A Perfect Day)

Un poco de chocolate

Una merienda en Ginebra (Un berenar a Ginebra) (TV)

V.O.S. (Versión original subtitulada)

Ventajas de viajar en tren

Vilafranca (TV)

Volverás

Vorvik

Yerma

Yo, puta 